\title{
Current Advances in Radiotherapy for Newly Diagnosed Glioblastoma Multiforme
}

Noriyuki Okonogi, Takahiro Oike, Katsuyuki Shirai, Tomoaki Tamaki, Shin-ei Noda, Yoshiyuki Suzuki and Takashi Nakano

Department of Radiation Oncology, Gunma University Graduate School of Medicine, Japan

\begin{abstract}
Glioblastoma multiforme is the most common adult primary brain tumor that is associated with very poor survival. The current standard therapy for newly diagnosed glioblastoma multiforme includes surgical resection and a combination of radiotherapy and chemotherapy with temozolomide. This treatment strategy leads to better overall survival; however, majority of tumor recurrences occur within the irradiated field. To overcome this problem, dose intensification is being tested in the management of glioblastoma multiforme.

In recent years, technological development of radiotherapies, such as intensity-modulated radiation therapy, stereotactic radio surgery, stereotactic radiation therapy, boron neutron capture therapy, and particle beam therapy, has improved dose distribution. Several prospective studies using these radiotherapies have shown that dose escalation is feasible and appears to be effective. Although the number of patients with glioblastoma multiforme in each study was not large, the survival times in these studies tended to be better than in those with standard dosing schedules. Dose escalation radiotherapy could be a hopeful strategy for patients with glioblastoma multiforme. In this review, we review advances in current radiotherapies for patients with newly diagnosed glioblastoma multiforme.
\end{abstract}

Keywords: Glioblastoma multiforme (GBM); Radiotherapy; Dose escalation; Intensity-modulated radiation therapy (IMRT); Particle beam therapy

\begin{abstract}
Abbreviations: GBM: Glioblastoma Multiforme; TMZ: Temozolomide; MST: Median Survival Time; MGMT: $\mathrm{O}^{6}$ Methylguanine-DNA Methyltransferase; RTOG: The Radiation Therapy Oncology Group; PET: Positron Emission Tomography; IGRT: Image-Guided Radiotherapy; 3D-CRT: Three-Dimensional Conformal Radiation Therapy; IMRT: Intensity-Modulated Radiation Therapy; SRS: Stereotactic Radio Surgery; SRT: Stereotactic Radiation Therapy; BNCT: Boron Neutron Capture Therapy
\end{abstract}

\section{Introduction}

Glioblastoma multiforme (GBM) is the most common primary brain tumor in adults, which accounts for approximately $70 \%$ of high-grade gliomas [1]. The prognosis of patients with GBM has been poor, with a median survival time (MST) of only approximately 15 months. Pretreatment patient characteristics such as age at diagnosis and Karnofsky performance status are the best predictors of survival [2]. The standard treatment for patients with GBM consists of maximal surgical resection followed by adjuvant chemoradiotherapy. A recent randomized trial showed that standard radiotherapy was associated with poor outcomes comparing short-course radiotherapy, especially in patients older than 70 years [3]. Both temozolomide (TMZ) alone and short-course radiotherapy alone would be considered as standard treatment options in elderly patients with GBM [3]. However, the efficacy of TMZ depends on the DNA-repair enzyme $\mathrm{O}^{6}$-methylguanine-DNA methyltransferase (MGMT) promoter status [3,4]. Thus, postoperative radiotherapy is considered for all patients with GBM.

The standard care is $60 \mathrm{~Gy}$ in $30-33$ fractions with concurrent TMZ for postoperative with newly diagnosed GBM except elderly or fragile patients $[3,4]$. Although the addition of TMZ has prolonged survival of these patients, the MST is approximately 15 months. To further improve overall survival, dose escalation to the target volume by innovations in radiotherapy is being tested. This review highlights dose escalation studies using modalities that deliver excellent dose distribution, which is expected to improve clinical outcomes.

\section{Advances in Radiotherapy}

\section{Historical context}

Historically, clinical studies of GBM have shown a dose-effect relationship with postoperative radiotherapy. In the 1970s, Walker et al. from the Brain Tumor Study Group discovered a radiation doseeffect relationship, and a dose of $60 \mathrm{~Gy}$ was established as the standard care [5]. Further dose intensification using higher radiation doses and altered fractionation was pursued but failed to provide a clear clinical benefit [6,7]. The Radiation Therapy Oncology Group (RTOG) and the Eastern Cooperative Oncology Group randomized 253 patients to either whole-brain irradiation with $60 \mathrm{~Gy}$ or $60 \mathrm{~Gy}$ plus a $10-\mathrm{Gy}$ boost to limited volume. The MSTs were 9.3 months and 8.2 months, respectively, with no additional benefit for the group receiving the higher irradiated doses [7]. Given these results, 60 Gy has been regarded as the standard dose in postoperative radiotherapy for patients with GBM and has been adopted in most clinical trials. However, with the majority of tumor recurrences occurring within the irradiated field and poor outcome being associated with standard therapy [8], the role of radiation dose intensification in the management of GBM has been undergoing further exploration.

\section{Advances in diagnostic imaging and radiotherapy techniques}

Diagnostic imaging plays key roles in radiotherapy for patients with GBM. Besides technological improvements in $\mathrm{x}$-ray imaging

*Corresponding author: Katsuyuki Shirai, Department of Radiation Oncology, Gunma University Graduate School of Medicine, Japan, Tel: +81-27-220-8383: Fax: +81-27-220-8397; E-mail: kshirai@gunma-u.ac.jp

Received October 04, 2013; Accepted January 24, 2014; Published February 05, 2014

Citation: Okonogi N, Oike T, Shirai K, Tamaki T, Noda SE, et al. (2014) Current Advances in Radiotherapy for Newly Diagnosed Glioblastoma Multiforme. J Neuro Neurophysiol 5: 186. doi:10.4172/2155-9562.1000186

Copyright: (c) 2014 Okonogi N, et al. This is an open-access article distributed under the terms of the Creative Commons Attribution License, which permits unrestricted use, distribution, and reproduction in any medium, provided the original author and source are credited. 
including computed tomography scans, recent advances in magnetic resonance imaging (MRI) and positron emission tomography (PET) have made possible the routine acquisition of physiological data [9]. Glioma cells are known to migrate along myelinated fibre tracts of the white matter and penetrate to the peritumoral edema [10]. In a pattern of failure study, Wallner et al. noted that $78 \%$ of unifocal recurrences occurred within $2-\mathrm{cm}$ of the initial tumor volume, defined as the enhancing edge of the tumor on computed tomography (CT) scan [11]. Pitzkall et al. showed metabolically active tumors extending outside the region defined on T2-weighted MRI in $88 \%$ patients with high-grade gliomas [12]. Recent studies have demonstrated the possibility that the ${ }^{11} \mathrm{C}$-methionine PET could distinguish infiltrative tumors from nontumor lesions [13]. These advances have contributed to establishing an appropriate definition for target volume, although their role in the noninvasive grading of the tumors is limited.

To date, there is no consensus on what volume constitutes the optimal target of radiotherapy. However, several studies have attempted to define the optimal target definition for GBM. The Canadian GBM committee established guidelines have been suggested that the clinical target volume (CTV) should be identified with T1 gadolinium-contrast-enhanced MRI with a margin of 2-3 cm [14]. Also, the current RTOG 0825 phase III trial recommends that the initial gross tumor volume (GTV) should be defined by either the T2 or the fluid-attenuated inversion recovery abnormality on the postoperative MRI. The initial CTV is defined as the GTV plus a margin of $2 \mathrm{~cm}$. In addition, they recommend that preoperative imaging should be used for correlation and improved identification [15]. In principle, inclusion of all radiographic data of tumor and peritumoral edema with generous margin while considering of dose limitation to critical structures is the rule in design of treatment plans.

Advances in radiation techniques include image-guided radiotherapy (IGRT), which makes it possible to verify the positions of the target volume and organs at risk during the treatment sessions. Using IGRT, the position of the target volume is known throughout movement and irradiation can be precisely targeted to the actual position of the tumor. This precise targeting results in a substantial decrease of planning target volume margins leading to reduction in the volume of normal tissue to which irradiation is prescribed. These advances in diagnostic imaging and radiotherapy techniques have contributed to researchers' attempts to intensify the radiation dose to the target volume.

Patient management decisions require an assessment of both initial responses to treatment as well as subsequent evidence of progressive disease. Previously, the most widely used criteria for assessing response to therapy in high-grade gliomas, the Macdonald Criteria, are based on two-dimensional tumor measurements on CT or MRI, in conjunction with clinical assessment and corticosteroid dose [16]. However, there are significant limitations to these criteria, which only address the contrast-enhancing component of the tumor. For example, chemoradiotherapy for newly diagnosed GBM in transient increase in tumor enhancement (pseudo-progression) in $20 \%$ to $30 \%$ of patients after the treatment, which is difficult to differentiate from true tumor progression [17]. In addition, pseudo-progression can develop during TMZ combination chemoradiotherapy in patients with malignant glioma [18]. Furthermore, antiangiogenic agents produce high radiographic response rates, as defined by a rapid decrease in contrast enhancement on CT/MRI that occurs within days of initiation of treatment and that is partly a result of reduced vascular permeability to contrast agents rather than a true antitumor effect [19]. Recently, new criteria have been proposed by the Response Assessment in NeuroOncology working group to address problems in assessing patients with pseudo-progression or in assessing progressive disease in patients with non-enhancing lesions [20].

\section{Potential of dose escalation in radiotherapy}

Nakagawa et al. showed a potential benefit of dose escalation in postoperative radiotherapy for patients with GBM by using threedimensional conformal radiation therapy (3D-CRT) (Table 1). They noted that postoperative radiotherapy with $90 \mathrm{~Gy}$ in 45 fractions in patients with GBM resulted in significantly fewer local failures than in those who received postoperative radiotherapy with $60-80 \mathrm{~Gy}$ in $30-40$ fractions; the local failure rates were $31 \%$ and $80 \%$ in the highdose and low-dose groups, respectively [21]. Furthermore, Tanaka et al. demonstrated that patients who received high-dose radiotherapy had significantly longer MSTs compared with those who received conventional radiotherapy. In this study, MST was 16.2 months for patients who received $80-90$ Gy in 40-45 fractions and 12.4 months for patients who received $60 \mathrm{~Gy}$ in 30 fractions [22]. These results suggest that dose escalation to the target volume can achieve better local control and longer survival of patients with GBM.

In contrast, as expected, radiation-induced white matter abnormalities with shorter onset were observed more frequently when high-dose radiotherapy was employed [22]. In their study, nine patients in the high-dose group developed radiation-induced necrosis, compared with none in the 60-Gy group: necrosis was confirmed pathologically from surgical samples in five patients and diagnosed clinically by PET in four patients. In addition, optic chiasm and nerve injury may manifest at 54-60 Gy, while onset of hormone insufficiency from irradiation of the hypothalamic-pituitary axis is variable but may be observed with doses as low as 20 Gy [23]. Therefore, an ingenious method is needed to decrease the risk of radiation-induced toxicity while maintaining a high dose to the target volume. The candidate modalities are intensity-modulated radiation therapy (IMRT), stereotactic radiosurgery (SRS), stereotactic radiation therapy (SRT), boron neutron capture therapy (BNCT), and particle beam therapy.

\section{Intensity modulated radiation therapy}

IMRT is an ingenious method for treatment of central nervous system malignancies [24]. Comparison of IMRT with 3D-CRT has clearly shown that IMRT improves target dose conformity, reduces doses to organs at risk (e.g., the brainstem, optic chiasm, lens, optic nerves, and cerebral cortex), and achieves comparable target coverage [25] (Figures 1a and 1b). Recently, dose escalation studies using IMRT showed prolongation of survival in patients with GBM with no increase in incidence of severe toxicity. Tsien et al. compared the efficacy of dose escalation using IMRT with concurrent TMZ [26]. They found that doses of 66-81 Gy over 30 fractions delivered by IMRT resulted in an MST of 20.1 months, and a lower in-field recurrence rate was observed in groups that received higher doses. In their study,_late Grade 3radiation-induced necrosis was observed at 78 Gy ( 2 of 7 patients) and 81 Gy (1 of 9 patients). No case of radiation-induced necrosis was observed at or below $75 \mathrm{~Gy}$. Median time to RT necrosis was 7 months (range: 5.4-8.9). The authors concluded that $75 \mathrm{~Gy}$ in 30 fractions could be safely delivered to patients with GBM using IMRT with concurrent TMZ. Iuchi et al. evaluated dose escalation using hypofractionated IMRT [27]. They found that the 1- and 2-year progression-free survival rates were and $71.4 \%$ and $53.6 \%$, respectively. Dose escalation showed significant improvement in both local control and patient survival. Although massive radiation-induced necrosis required a second 
Citation: Okonogi N, Oike T, Shirai K, Tamaki T, Noda SE, et al. (2014) Current Advances in Radiotherapy for Newly Diagnosed Glioblastoma Multiforme. J Neurol Neurophysiol 5: 186. doi:10.4172/2155-9562.1000186

Page 3 of 6

\begin{tabular}{|c|c|c|c|c|c|c|}
\hline Author & Treatment & Fraction Size & Chemotherapy Agents & $\begin{array}{l}\text { No. of } \\
\text { patients }\end{array}$ & Survival & Adverse events \\
\hline $\begin{array}{l}\text { Nakagawa K } \\
\text { et al. } \\
(21)\end{array}$ & 3D-CRT & $\begin{array}{l}60-80 \mathrm{~Gy} / 30-40 \mathrm{fr} . \\
\text { versus } 90 \mathrm{~Gy} / 45 \mathrm{fr} .\end{array}$ & $\begin{array}{l}\text { Nimustine } 1 \mathrm{mg} / \mathrm{m}^{2} \text { plus } \\
\text { vincristine } 80 \mathrm{mg} / \mathrm{m}^{2} \text { on Days } 1 \\
\text { and } 28 \text {, and nimustine }\end{array}$ & 38 & $\begin{array}{l}\text { The 1-year, 2-year, } \\
5 \text {-year, and 10-year } \\
\text { overall survival rates } \\
\text { were } 75 \%, 42 \%, 20 \% \text {, } \\
\text { and } 15 \% \text {, respectively. }\end{array}$ & $\begin{array}{l}\text { Two among } 16 \text { patients of the } \\
\text { higher dose group developed } \\
\text { radiation necrosis. One patient died } \\
\text { of radiation necrosis. }\end{array}$ \\
\hline $\begin{array}{c}\text { Tanaka } \mathrm{M} \text { et al. } \\
(22)\end{array}$ & 3D-CRT & $80-90 \mathrm{~Gy} / 40-45$ fr. & $\begin{array}{l}\text { Nimustine or carmustine with or } \\
\text { without vincristine }\end{array}$ & 90 & 16.2 months in MST & $\begin{array}{l}\text { Nine patients developed radiation } \\
\text { necrosis, }\end{array}$ \\
\hline $\begin{array}{l}\text { Tsien } \mathrm{Cl} \text { et al. } \\
(26)\end{array}$ & IMRT & $66-81 \mathrm{~Gy} / 30 \mathrm{fr}$. & $\begin{array}{l}\text { Concomitant temozolomide } 75 \\
\mathrm{mg} / \mathrm{m}^{2} \text { daily for } 6 \text { weeks }\end{array}$ & 38 & 20.1 months in MST & $\begin{array}{l}\text { Three among } 16 \text { patients received } \\
78 \text { Gy or higher dose developed } \\
\text { radiation necrosis. }\end{array}$ \\
\hline $\begin{array}{l}\text { luchi T et al. } \\
\text { (27) }\end{array}$ & IMRT & $48-68 \mathrm{~Gy} / 8 \mathrm{fr}$. & (not described in detail) & 25 & $\begin{array}{l}\text { The 1-year and 2-year } \\
\text { overall survival rates } \\
\text { were } 71.4 \% \text { and } \\
55.6 \% \text {, respectively. }\end{array}$ & $\begin{array}{l}\text { Three among } 25 \text { patients } \\
\text { developedmassive radiation } \\
\text { necrosis and required } \\
\text { secondsurgery. }\end{array}$ \\
\hline $\begin{array}{l}\text { Souhami L } \\
\text { et al. } \\
\text { (32) }\end{array}$ & 3D-CRT+SRS & $\begin{array}{l}60 \mathrm{~Gy} / 30 \text { fr. with } \\
\text { 3D-CRT plus } 15-24 \\
\text { Gy with }\end{array}$ & $\begin{array}{l}\text { Carmustine } 80 \mathrm{mg} / \mathrm{m}^{2} \text { in days } 1-3 \\
\text { every } 8 \text { weeks for six }\end{array}$ & 89 & 13.5 months in MST & $\begin{array}{l}\text { Four patients who received a } 15-G y \\
\text { boost developed radiation necrosis. }\end{array}$ \\
\hline $\begin{array}{l}\text { Fitzek MM } \\
\text { et al. } \\
(42)\end{array}$ & $\begin{array}{l}\text { 3D-CRT+proton } \\
\text { radiotherapy }\end{array}$ & $\begin{array}{l}45 \mathrm{~Gy} / 25 \text { fr. with } \\
\text { 3D-CRT plus } 45 \\
\text { GyE/25 fr. with protons, }\end{array}$ & (unused) & 23 & 20.0 months in MST & $\begin{array}{l}\text { Seven patients developed radiation } \\
\text { necrosis, }\end{array}$ \\
\hline $\begin{array}{l}\text { Mizumoto M } \\
\text { et al. } \\
\text { (43) }\end{array}$ & 3D-CRT+proton & $\begin{array}{l}50.4 \text { Gy/28fr. with } \\
\text { 3D-CRT plus } 46.2 \\
\text { GyE/28 fr. with protons }\end{array}$ & $\begin{array}{l}\text { Nimustine hydrochloride } 80 \mathrm{mg} / \\
\mathrm{m}^{2} \text { during the first and fourth } \\
\text { weeks }\end{array}$ & 20 & 21.6 months in MST & $\begin{array}{l}\text { Late radiation-induced necrosis and } \\
\text { leukoencephalopathy were each } \\
\text { seen in only one among } 20 \text { patients. }\end{array}$ \\
\hline $\begin{array}{c}\text { Mizoe JE et al. } \\
(47)\end{array}$ & $\begin{array}{l}\text { 3D-CRT+Carbon } \\
\text { ion }\end{array}$ & $\begin{array}{l}50 \text { Gy/25 fr. with } \\
\text { 3D-CRT plus } 16.8- \\
\text { 24.8/8 fr. with carbon } \\
\text { ions }\end{array}$ & $\begin{array}{l}\text { Nimustine hydrochloride on the } \\
1 \mathrm{st} \text { and } 4 \text { th or } 5 \text { th weeks of the } \\
\text { x-ray at a dose of } 100 \mathrm{mg} / \mathrm{m} 2\end{array}$ & 32 & 26.0 months in MST & $\begin{array}{l}\text { Four patients developed Grade } 2 \\
\text { brain toxicity. No case of Grade } 3 \text { or } \\
\text { higher brain toxicity was observed. }\end{array}$ \\
\hline
\end{tabular}

Abbreviations:

3D-CRT, 3-dimensional conformal radiotherapy; fr, fractions; MST, median survival time; IMRT, intensity modulated radiation therapy; SRS, stereotactic radiosurgery; CNS, central nervous system; CGE, cobalt gray equivalent

Table 1: Results of recent dose escalation studies with external beam radiotherapy.
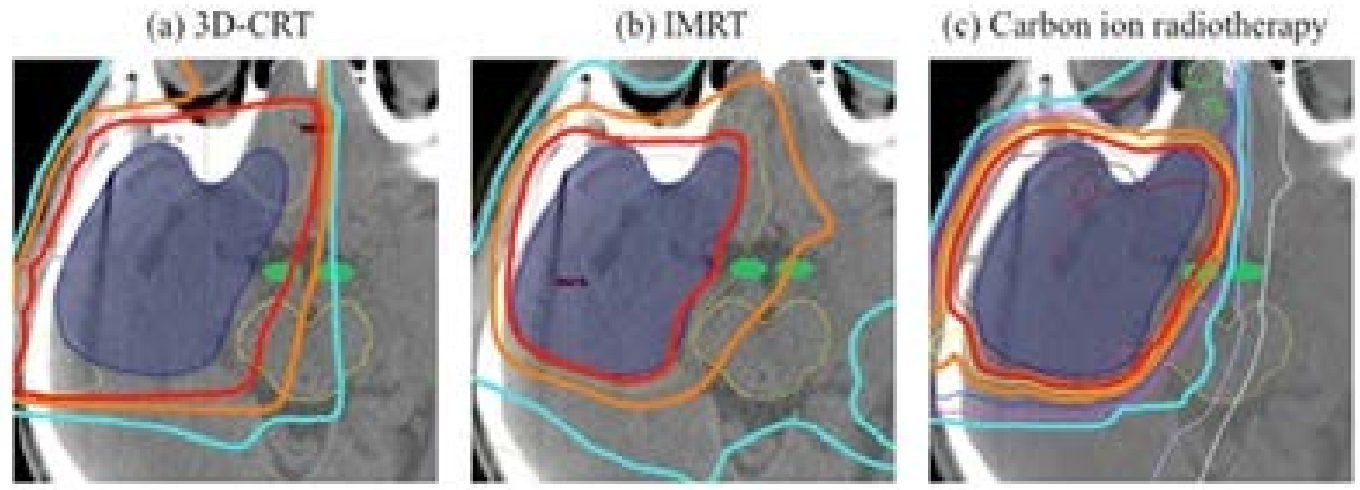

Figure 1: (a) 3D-CRT, (b) IMRT, and (c) Carbon ion radiotherapy. Representative axial dose distribution for three-dimensional conformal radiation therapy (3D-CRT) plan (4 ports), intensity-modulated radiation therapy (IMRT) plan ( 9 ports), and carbon ion radiotherapy (4 ports) plan. The cyan-, orange-, and red-colors show $50 \%$, $80 \%$, and $95 \%$ isodose lines, respectively. The dark blue-, green-, and yellow-colors show the target volume, optic nerves, and brain stem, respectively.

surgery in 3 of 25 cases in this study, dose escalation using IMRT may contribute to better survival in patients with GBM.

\section{Stereotactic radiosurgery and Stereotactic radiation therapy}

SRS and SRT are forms of hypofractionated high-precision radiotherapy delivery [28]. To date, several clinical studies on SRS and SRT have been conducted in patients newly diagnosed with GBM [2931]. RTOG 93-05, the only randomized controlled trial on this topic, tested the benefits of administering SRS before conformal radiotherapy with bis-chloroethylnitrosourea (BCNU) in 186 patients with GBM [32]. These patients were randomized into the following two groups: 97 patients received conformal radiotherapy and BCNU and 89 patients received SRS 1 week prior to conformal radiotherapy and BCNU.
The tumor dose delivered was volume-dependent, ranging from 15 to 24 Gy in compliance with the established maximum safely tolerated doses [33]. This randomized trial showed no significant difference in MST or patterns of failure with the addition of SRS in patients with GBM. Although this study provides Level I evidence against the use of SRS prior to conformal radiotherapy with BCNU, it raises several important issues with respect to study applicability, including timing of SRS, type of chemotherapy (BCNU vs. TMZ), and extent of surgical resection. Further clinical trials to test these issues are warranted.

\section{Boron neutron capture therapy}

BNCT is a two-step technique. First, compounds labeled with ${ }^{10}$ boron are injected into the patient and, depending on the tumor 
entity, the injected compounds are selectively enriched in tumor cells [34]. Second, patients are irradiated with low-energy neutrons from a nuclear reactor or fast neutrons from cyclotron. The ${ }^{10}$ boron in the tumor cells and the thermal neutrons react [boron neutron capture reaction: ${ }^{10} \mathrm{~B}$ (n, alpha) ${ }^{7} \mathrm{Li}$ ] and release high linear-transfer alpha particles and 7lithium [35]. Because the alpha particles have a limited range of $5-9 \mu \mathrm{m}$, the therapeutic irradiation is limited to the cells with a high concentration of boron.

Several hundred patients with GBM have been treated with BNCT in phase I and II studies in Europe, the United States, and Japan; the survival period in these studies was comparable with those obtained with standard radiotherapy [34-38]. These studies resulted in an MST of 13.0-17.6 months, which was equal to or better than that of concurrent chemoradiotherapy [4]. However, no randomized trials comparing BNCT with standard therapy have been undertaken. Toxicities are typically acute and related to a temporal increase in intracranial pressure. A residual tumor volume of greater than or equal to $60 \mathrm{~cm}^{3}$ led to a greater incidence of acute central nervous system toxicity $[35,37]$.

Considerable efforts over the past 20 years to design and synthesize boron-containing compounds capable of selectively achieving sufficient boron concentrations in tumor cells have been unsuccessful. Moreover, methods for transport and delivery of boronated pharmacophores to the hypovascular region or G0 phase cells of the tumor are needed. The relatively high costs associated with the construction of the neutron beam appear to have been the main factor inhibiting the evolution of a technique. Despite these obstacles, considerable improvements in the efficiency and specificity of the delivery of boronated agents may provide the driving force that will bring the technique into the main stream of treatments for patients with GBM.

\section{Particle beam therapy}

Charged particle beams consisting of protons and carbon ions have the Bragg peak and allow highly localized deposition of energy that can be used for increasing radiation doses to targets while minimizing irradiation to adjacent normal tissues [39]. Proton radiotherapy has been carried out in the United States, Europe, and Japan. Carbon ion radiotherapy has been carried out in five institutions, and most clinical data have been provided by the National Institute of Radiological Science, Japan $[40,41]$.

\section{Proton radiotherapy}

Clinical trials with proton radiotherapy have been conducted for patients with GBM. Fitzek et al. conducted a phase II study of 23 patients with GBM treated with $90 \mathrm{GyE}$ utilizing protons and x-rays in the hyper fractionated radiotherapy [42]. All patients developed new areas of gadolinium enhancement within the high radiation dose regions during the follow-up period. While tissues obtained at biopsy, resection, or autopsy were histologically examined in 15 of 23 patients, radiation necrosis was confirmed only in seven patients. The MST of all the patients was 20.0 months, and the survival of the patients who developed radiation necrosis was significantly longer than that of the other patients._Recently, Mizumoto et al. conducted a phase I/II study of postoperative hyperfractionated concomitant boost proton beam therapy with nimustine hydrochloride in patients with GBM [43]. In their study, the MST was 21.6 months while acute toxicity was mainly hematologic and controllable. Late radiation-induced necrosis and leukoencephalopathy were each seen in only one of 20 patients. These studies showed the clinical usefulness of proton radiotherapy and suggested the possibility of doseescalation in the treatment of patients with GBM using proton radiotherapy.

\section{Carbon ion radiotherapy}

Carbon ion radiotherapy can offer better dose conformity to a target volume than other modalities [44]. In addition, high linear energy transfer (LET) radiation, such as carbon ion beams, has greater biological effectiveness than low LET radiation, such as x-rays and proton beams. Because of its better dose distribution and cell-killing potency, carbon ion radiotherapy is a promising modality in the treatment of patients with GBM $[45,46]$ (Figure 1c).

Mizoe et al. reported a phase I/II study of 32 patients with GBM and 16 patients with anaplastic astrocytoma treated with surgery and postoperative concurrent chemoradiotherapy with $\mathrm{x}$-rays followed by carbon ion radiotherapy [47]. The treatment consisted of $50 \mathrm{~Gy}$ of $\mathrm{x}$-ray radiotherapy in 25 fractions with concurrent administration of nimustine hydrochloride and carbon ion radiotherapy with the doses increased from 16.8 to $24.8 \mathrm{GyE}$ in $10 \%$ incremental steps. There was no Grade 3 or higher acute toxicity in the brain. The late reactions included four cases of Grade 2 brain toxicity among 48 cases. TMZ was not administered in this study.

Evaluation of the efficacy of concurrent chemo-carbon ion radiotherapy using TMZ is warranted. Combs et al. conducted a randomized phase II study in patients with GBM, in which they compared carbon ion radiotherapy and proton radiotherapy as a boost following 50 Gy of x-ray radiotherapy with concurrent TMZ [48]. In a report of early treatment results of this study, little toxicity was associated with the treatment [49]. This study by Rieken is expected to evaluate the efficacy of dose escalation using particle beam therapy.

\section{Radiation-induced toxicities}

Dose-related toxicities for surrounding normal structures should be considered when we postulate dose escalation strategy. A necrosis is one of the most bothersome radiation-induced toxicities. As we described above, even with modalities which deliver excellent dose distribution, dose escalation strategy can develop radiation-induced necrosis because that the surrounding normal tissue adjacent to the fatal lesion is usually included in the target volume. Thus, dose escalation strategy for patients with GBM not only has the therapeutic potential but also provides a difficult challenge in practice.

Recently, new evidences support a role of antiangiogenic therapy, such as bevacizumab, for the treatment of radiation necrosis $[50,51]$. This antiangiogenic therapy may be effective in patients with radiation necrosis after dose-escalation radiotherapy. In addition, a recent study in which bevacizumab was added to a hypofractionated course of reirradiation in recurrent gliomas showed that no radiation-induced necrosis was observedin 25 patients who were studied [52]. The addition of bevacizumab to chemoradiation may increase the therapeutic ratio through possible antitumor effects and may also allow safe escalation of radiotherapy by reducing the risk of radiation-induced necrosis.

\section{Conclusions}

Despite state-of-the-art oncological therapy that includes maximum safe surgical resection and radiotherapy, the prognosis of patients with GBM remains poor. Several prospective studies using modalities that deliver excellent dose distribution of radiotherapy have shown that dose escalation is feasible and appears to be effective. It is remarkable that the dose escalation strategy can change the pattern of failure. Thus, doses of radiotherapy higher than $60 \mathrm{~Gy}$ are needed 
Citation: Okonogi N, Oike T, Shirai K, Tamaki T, Noda SE, et al. (2014) Current Advances in Radiotherapy for Newly Diagnosed Glioblastoma Multiforme. J Neurol Neurophysiol 5: 186. doi:10.4172/2155-9562.1000186

within irradiated field to control GBM. However, the strategy could come with limitations that include severe toxicities, such as radiation necrosis in the fatal region. Patients with GBM being treated with dose escalation radiotherapy need to be studied to identify the suitable target volume, dose fractionation. Further prospective trials with large numbers of patients are warranted to establish the efficacy of these advanced radiotherapy treatments for patients with GBM.

\section{Acknowledgments}

This work was supported by Grants-in-Aid from the Ministry of Education, Culture, Sports, Science and Technology of Japan for Scientific Research in Innovative Areas, and from the Japan Society for the Promotion of Science for Young Scientists, KAKENHI (Katsuyuki Shirai, grant number: 24791277).The authors have no competing interests to declare.

\section{References}

1. Wen PY, Kesari S (2008) Malignant gliomas in adults. N Engl J Med 359: 492507.

2. Scott CB, Scarantino C, Urtasun R, Movsas B, Jones CU, et al. (1998) Validation and predictive power of Radiation Therapy Oncology Group (RTOG) recursive partitioning analysis classes for malignant glioma patients: a report using RTOG 90-06. Int J Radiat Oncol Biol Phys 40: 51-55.

3. Malmström A, Grønberg BH, Marosi C, Stupp R, Frappaz D, et al. (2012) Temozolomide versus standard 6-week radiotherapy versus hypofractionated radiotherapy in patients older than 60 years with glioblastoma: the Nordic randomised, phase 3 trial. Lancet Oncol 13: 916-926.

4. Stupp R, Mason WP, van den Bent MJ, Weller M, Fisher B, et al. (2005) Radiotherapy plus concomitant and adjuvant temozolomide for glioblastoma. N Engl J Med 352: 987-996.

5. Walker MD, Strike TA, Sheline GE (1979) An analysis of dose-effect relationship in the radiotherapy of malignant gliomas. Int J Radiat Oncol Biol Phys 5: 17251731.

6. Loeffler JS, Alexander E 3rd, Shea WM, Wen PY, Fine HA, et al. (1992) Radiosurgery as part of the initial management of patients with malignant gliomas. J Clin Oncol 10: 1379-1385.

7. Nelson DF, Diener-West M, Horton J, Chang CH, Schoenfeld D, et al. (1988) Combined modality approach to treatment of malignant gliomas--re-evaluation of RTOG 7401/ECOG 1374 with long-term follow-up: a joint study of the Radiation Therapy Oncology Group and the Eastern Cooperative Oncology Group. NCl Monogr 6: 279-284.

8. Milano MT, Okunieff P, Donatello RS, Mohile NA, Sul J, et al. (2010) Patterns and timing of recurrence after temozolomide-based chemoradiation for glioblastoma. Int J Radiat Oncol Biol Phys 78: 1147-1155.

9. Nelson SJ, Cha S (2003) Imaging glioblastoma multiforme. Cancer J 9: 134145.

10. Giese A, Westphal M (1996) Glioma invasion in the central nervous system. Neurosurgery 39: 235-250.

11. Wallner KE, Galicich JH, Krol G, Arbit E, Malkin MG (1989) Patterns of failure following treatment for glioblastoma multiforme and anaplastic astrocytoma. Int J Radiat Oncol Biol Phys 16: 1405-1409.

12. Pirzkall A, McKnight TR, Graves EE, Carol MP, Sneed PK, et al. (2001) MRspectroscopy guided target delineation for high-grade gliomas. Int J Radiat Oncol Biol Phys 50: 915-928.

13. Li DL, Xu YK, Wang QS, Wu HB, Li HS (2012) ${ }^{11} \mathrm{C}$-methionine and ${ }^{18} \mathrm{~F}$-fluorodeoxyglucose positron emission tomography/CT in the evaluation of patients with suspected primary and residual/recurrent gliomas. Chin Med J (Engl) 125: 91-96.

14. Mason WP, Maestro RD, Eisenstat D, Forsyth P, Fulton D, et al. (2007) Canadian recommendations for the treatment of glioblastoma multiforme. Curr Oncol 14: 110-117.

15. http://www.rtog.org/ClinicalTrials/ProtocolTable/StudyDetails. aspx?study $=0825$

16. Macdonald DR, Cascino TL, Schold SC Jr, Cairncross JG (1990) Response criteria for phase II studies of supratentorial malignant glioma. J Clin Oncol 8: $1277-1280$.
17. Brandsma D, Stalpers L, Taal W, Sminia P, van den Bent MJ (2008) Clinical features, mechanisms, and management of pseudoprogression in malignant gliomas. Lancet Oncol 9: 453-461.

18. Suzuki Y, Saleem W, Satoh Y, Wakatsuki M, Shirai K, et al. (2012) Pseudoprogression event during temozolomide combining chemoradiotherapy for malignant glioma. Austral-Asian Journal of Cancer 11: 131-135.

19. Batchelor TT, Sorensen AG, di Tomaso E, Zhang WT, Duda DG, et al. (2007) AZD2171, a pan-VEGF receptor tyrosine kinase inhibitor, normalizes tumor vasculature and alleviates edema in glioblastoma patients. Cancer Cell 11: 8395.

20. Wen PY, Macdonald DR, Reardon DA, Cloughesy TF, Sorensen AG, et al (2010) Updated response assessment criteria for high-grade gliomas: response assessment in neuro-oncology working group. J Clin Oncol 28: 1963-1972.

21. Nakagawa K, Aoki Y, Fujimaki T, Tago M, Terahara A, et al. (1998) High-dose conformal radiotherapy influenced the pattern of failure but did not improve survival in glioblastoma multiforme. Int J Radiat Oncol Biol Phys 40: 1141-1149.

22. Tanaka M, Ino Y, Nakagawa K, Tago M, Todo T (2005) High-dose conformal radiotherapy for supratentorial malignant glioma: a historical comparison. Lancet Oncol 6: 953-960.

23. Emami B, Lyman J, Brown A, Coia L, Goitein M, et al. (1991) Tolerance of normal tissue to therapeutic irradiation. Int J Radiat Oncol Biol Phys 21: 109 122.

24. Narayana A, Yamada J, Berry S, Shah P, Hunt M, et al. (2006) Intensitymodulated radiotherapy in high-grade gliomas: clinical and dosimetric results. Int J Radiat Oncol Biol Phys 64: 892-897.

25. Chan MF, Schupak K, Burman C, Chui CS, Ling CC (2003) Comparison of intensity-modulated radiotherapy with three-dimensional conformal radiation therapy planning for glioblastoma multiforme. Med Dosim 28: 261-265.

26. Tsien Cl, Brown D, Normolle D, Schipper M, Piert M, et al. (2012) Concurrent temozolomide and dose-escalated intensity-modulated radiation therapy in newly diagnosed glioblastoma. Clin Cancer Res 18: 273-279.

27. luchi T, Hatano K, Narita Y, Kodama T, Yamaki T, et al. (2006) Hypofractionated high-dose irradiation for the treatment of malignant astrocytomas using simultaneous integrated boost technique by IMRT. Int J Radiat Oncol Biol Phys 64: 1317-1324.

28. LEKSELL L (1951) The stereotaxic method and radiosurgery of the brain. Acta Chir Scand 102: 316-319.

29. Yoshikawa K, Saito K, Kajiwara K, Nomura S, Ishihara H, et al. (2006) CyberKnife stereotactic radiotherapy for patients with malignant glioma. Minim Invasive Neurosurg 49: 110-115.

30. Biswas T, Okunieff P, Schell MC, Smudzin T, Pilcher WH, et al. (2009) Stereotactic radiosurgery for glioblastoma: retrospective analysis. Radiat Oncol 4: 11.

31. Villavicencio AT, Burneikiene S, Romanelli P, Fariselli L, McNeely L, et al. (2009) Survival following stereotactic radiosurgery for newly diagnosed and recurrent glioblastoma multiforme: a multicenter experience. Neurosurg Rev 32: $417-424$

32. Souhami L, Seiferheld W, Brachman D, Podgorsak EB, Werner-Wasik M, et al. (2004) Randomized comparison of stereotactic radiosurgery followed by conventional radiotherapy with carmustine to conventional radiotherapy with carmustine for patients with glioblastoma multiforme: report of Radiation Therapy Oncology Group 93-05 protocol. Int J Radiat Oncol Biol Phys 60: 853860

33. Shaw E, Scott C, Souhami L, Dinapoli R, Kline R, et al. (2000) Single dose radiosurgical treatment of recurrent previously irradiated primary brain tumors and brain metastases: final report of RTOG protocol 90-05. Int J Radiat Oncol Biol Phys 47: 291-298.

34. Yamamoto T, Nakai K, Matsumura A (2008) Boron neutron capture therapy for glioblastoma. Cancer Lett 262: 143-152.

35. Barth RF, Coderre JA, Vicente MG, Blue TE (2005) Boron neutron capture therapy of cancer: current status and future prospects. Clin Cancer Res 11: 3987-4002.

36. Sköld K, Gorlia T, Pellettieri L, Giusti V, H-Stenstam B, et al. (2010) Boron neutron capture therapy for newly diagnosed glioblastoma multiforme: an assessment of clinical potential. Br J Radiol 83: 596-603. 
Citation: Okonogi N, Oike T, Shirai K, Tamaki T, Noda SE, et al. (2014) Current Advances in Radiotherapy for Newly Diagnosed Glioblastoma Multiforme. J Neurol Neurophysiol 5: 186. doi:10.4172/2155-9562.1000186

37. Chanana AD, Capala J, Chadha M, Coderre JA, Diaz AZ, et al. (1999) Boron neutron capture therapy for glioblastoma multiforme: interim results from the phase I/II dose-escalation studies Neurosurgery 44: 1182-1192.

38. Kawabata S, Miyatake S, Hiramatsu R, Hirota Y, Miyata S, et al. (2011) Phase II clinical study of boron neutron capture therapy combined with X-ray radiotherapy/temozolomide in patients with newly diagnosed glioblastoma multiforme--study design and current status report. Appl Radiat Isot 69: 17961799.

39. Schulz-Ertner D, Jäkel O, Schlegel W (2006) Radiation therapy with charged particles. Semin Radiat Oncol 16: 249-259.

40. Okada T, Kamada T, Tsuji H, Mizoe JE, Baba M, et al. (2010) Carbon ion radiotherapy: clinical experiences at National Institute of Radiological Science (NIRS). J Radiat Res 51: 355-364.

41. Ohno T, Kanai T, Yamada S, Yusa K, Tashiro M, et al. (2011) Carbon Ion Radiotherapy at the Gunma University Heavy Ion Medical Center: New Facility Set-up. Cancers (Basel) 3: 4046-4060.

42. Fitzek MM, Thornton AF, Rabinov JD, Lev MH, Pardo FS, et al. (1999) Accelerated fractionated proton/photon irradiation to 90 cobalt gray equivalent for glioblastoma multiforme: results of a phase II prospective trial. J Neurosurg 91: 251-260

43. Mizumoto M, Tsuboi K, Igaki H, Yamamoto T, Takano S, et al. (2010) Phase I/II trial of hyperfractionated concomitant boost proton radiotherapy for supratentorial glioblastoma multiforme. Int J Radiat Oncol Biol Phys 77: 98-105.

44. Suit H, DeLaney T, Goldberg S, Paganetti H, Clasie B, et al. (2010) Proton vs carbon ion beams in the definitive radiation treatment of cancer patients. Radiother Oncol 95: 3-22.

45. Blakely EA (1992) Cell inactivation by heavy charged particles. Radiat Environ Biophys 31: 181-196.
46. Castro JR, Saunders WM, Tobias CA Chen GT, Curtis S, et al. (1982) Treatment of cancer with heavy charged particles. Int J Radiat Oncol Biol Phys 8: 2191-2198.

47. Mizoe JE, Tsujii H, Hasegawa A, Yanagi T, Takagi R, et al. (2007) Phase I/I clinical trial of carbon ion radiotherapy for malignant gliomas: combined X-ray radiotherapy, chemotherapy, and carbon ion radiotherapy. Int J Radiat Oncol Biol Phys 69: 390-396.

48. Combs SE, Kieser M, Rieken S, Habermehl D, Jäkel O, et al. (2010) Randomized phase II study evaluating a carbon ion boost applied after combined radiochemotherapy with temozolomide versus a proton boost after radiochemotherapy with temozolomide in patients with primary glioblastoma: the CLEOPATRA trial. BMC Cancer 10: 478.

49. Rieken S, HabermehI D, Haberer T, Jaekel O, Debus J, et al. (2012) Proton and carbon ion radiotherapy for primary brain tumors delivered with active raster scanning at the Heidelberg lon Therapy Center (HIT): early treatment results and study concepts. Radiat Oncol 7: 41.

50. Torcuator R, Zuniga R, Mohan YS, Rock J, Doyle T, et al. (2009) Initia experience with bevacizumab treatment for biopsy confirmed cerebral radiation necrosis. J Neurooncol 94: 63-68.

51. Levin VA, Bidaut L, Hou P, Kumar AJ, Wefel JS, et al. (2011) Randomized double-blind placebo-controlled trial of bevacizumab therapy for radiation necrosis of the central nervous system. Int J Radiat Oncol Biol Phys 79: 14871495

52. Gutin PH, Iwamoto FM, Beal K, Mohile NA, Karimi S, et al. (2009) Safety and efficacy of bevacizumab with hypofractionated stereotactic irradiation for recurrent malignant gliomas. Int J Radiat Oncol Biol Phys 75: 156-163.
This article was originally published in a special issue, Brain Tumor handled by Editor(s). Dr. Colleen Dockstader, The Hospital for Sick Children, Canada 